\title{
Oficina Gurias na Computação: três horas de imersão feminina na área da Computação discutidas em detalhes
}

\author{
Flávia Amin ${ }^{1}$, Jaqueline Moura ${ }^{1}$, Karina Fernandes ${ }^{1}$, Ketrin $\operatorname{Vargas}^{1}$, Aline Mello ${ }^{1}$ \\ ${ }^{1}$ Universidade Federal do Pampa (UNIPAMPA) \\ Av. Tiaraju, 810 - 97546-550 - Alegrete - RS - Brazil \\ \{flaviaamin, moura.jak, casolafernandes, ketrindiovana53\}@gmail.com \\ alinemello@unipampa.edu.br
}

\begin{abstract}
The statistics indicate that women represent approximately $14 \%$ of the students who start an undergraduate degree program in Computing in Brazil. Many projects have performed workshops to high school students, aiming to attract more women to these programs. However, most of the studies found on these workshops do not bring enough information to allow their replication. This paper presents in detail the planning and execution of a 3-hour workshop focused on high School students, besides supplying all the material used.
\end{abstract}

Resumo. As estatísticas apontam que as mulheres representam aproximadamente $14 \%$ dos ingressantes nos cursos da área da Computação no Brasil. Muitos projetos têm realizado oficinas junto a estudantes do Ensino Médio, visando a atrair mais mulheres para esses cursos. Entretanto, a maioria dos trabalhos encontrados que relatam essas oficinas não trazem informações suficientes que permitam a sua replicação. Assim, este artigo apresenta em detalhe o planejamento e a execução de uma oficina de 3 horas voltada para estudantes do Ensino Médio, além de fornecer todo o material utilizado.

\section{Introdução}

As estatísticas da educação superior em Computação [SBC 2017] indicam que as mulheres representaram 13,80\% do total de ingressantes nos cursos de Computação no Brasil no ano de 2017. Essa realidade é a mesma observada na Universidade Federal do Pampa Campus Alegrete, em que as mulheres ingressantes nos cursos de Ciência da Computação e Engenharia de Software representaram 14\% no ano de 2019.

A ação de extensão Gurias na Computação da Universidade Federal do Pampa, parceira do programa Meninas Digitais, foi criada em 2016 com o objetivo de promover a participação feminina na área da Computação. As primeiras iniciativas se deram através da participação de mulheres em ações de divulgação dos cursos e a realização de encontros e fóruns destinados às graduandas e às mulheres da comunidade [Ferrão et al. 2017]. Com a baixa procura do público feminino pelos cursos de Computação, decidimos ampliar as ações voltadas às estudantes da Educação Básica.

Muitos projetos têm realizado ações para divulgar a área da Computação e ampliar a participação feminina. Analisando os anais do Women in Information Technology (WIT) nos anos de 2017 e 2018, 8 trabalhos abordaram a estratégia de realizar oficinas para apresentar a Computação para estudantes do Ensino Médio. Os 
trabalhos de [Santos et al. 2017b], [Salgado et al. 2017], [Ridel et al. 2018] mencionaram oficinas realizadas em um único encontro, enquanto [Neto and Casagranda 2017], [Santos et al. 2017a], [Soares et al. 2018], [Silva and Silva 2018] e [Moura et al. 2018] indicaram realizar oficinas com vários encontros. À exceção de [Salgado et al. 2017], os trabalhos não apresentam informações suficiente que permitam sua replicação.

Neste contexto, o presente trabalho descreve em detalhes o planejamento e a execução da oficina Gurias na Computação, que tem como propósito despertar o interesse de meninas do Ensino Médio pela Computação. O restante deste artigo está organizado como segue: a Seção 2 descreve os materiais e métodos adotados; os resultados obtidos são descritos na Seção 3; e, por fim, as considerações finais são apresentadas na Seção 4.

\section{Materiais e Métodos}

A equipe executora da oficina foi composta por uma docente e nove graduandas dos cursos de Computação da Universidade Federal do Pampa - Campus Alegrete. A ação foi organizada de forma colaborativa em encontros presenciais e através de ferramentas de colaboração e comunicação, como Google Drive e WhatsApp.

A duração da oficina foi a primeira decisão a ser tomada. A oficina foi realizada em apenas um encontro porque seu objetivo não seria atingido na íntegra se conteúdos abordados não fossem explorados, devido à ausências ou abandonos. Outra decisão foi em relação ao público alvo. A oficina foi realizada exclusivamente para meninas para que elas estivessem em um ambiente agradável e favorável a aprendizagem, livre do julgamento e das piadas dos meninos. Essa escolha impactou na realização da oficina no contraturno da escola.

O conteúdo da oficina foi assunto de muitas conversas da equipe executora. A oficina foi dividida em cinco etapas, as quais são apresentadas na Tabela 1. Todas as etapas foram apoiadas por uma apresentação de slides com modelo inspirado em revista em quadrinhos, a fim de chamar atenção das estudantes. Devido às diferentes necessidades de cada etapa, as três etapas iniciais foram realizadas em um sala tradicional (permitindo diferentes configurações) e as duas etapas finais foram desenvolvidas em um laboratório de informática. Cada etapa é detalhada a seguir.

Tabela 1. Etapas da oficina com a duração em minutos

\begin{tabular}{|l|l|l|}
\hline Etapa & Descrição & Duração \\
\hline Recepção & Registro de presença & $10 \mathrm{~min}$ \\
& Dinâmica de apresentação das participantes & $15 \mathrm{~min}$ \\
\hline Cursos e Projeto & Apresentação dos cursos da área da Computação & $20 \mathrm{~min}$ \\
& Apresentação do projeto e suas motivações & $10 \mathrm{~min}$ \\
\hline Computação & Definição da computação e seus problemas & $5 \mathrm{~min}$ \\
& Apresentação de mulheres protagonistas & $5 \mathrm{~min}$ \\
& Definição de algoritmos & $5 \mathrm{~min}$ \\
\hline Experimentação & Computação desplugada & $30 \mathrm{~min}$ \\
& Programação com blocos & $70 \mathrm{~min}$ \\
\hline Encerramento & Avaliação da oficina e vídeo final & $10 \mathrm{~min}$ \\
\hline
\end{tabular}

Na etapa Recepção, as estudantes assinaram a lista de presença e preencheram 
o formulário online de identificação que continha o nome completo, idade, nome da escola, série, e-mail e/ou telefone de contato. Em seguida, foi realizada uma dinâmica de apresentação utilizando uma bola, visando a maximizar a interação entre as participantes e ter um momento de descontração logo no início da oficina. A dinâmica consistia em realizar um círculo com as participantes em pé, então a participante que possuía a bola dizia seu nome e a atirava para alguém que ainda não tivesse se apresentado. Ao final da dinâmica, todas haviam falado seu nome e estavam mais à vontade.

A etapa Cursos e Projeto iniciou com a apresentação dos cursos de Computação da Universidade. Essa apresentação foi conduzida pelos coordenadores dos cursos (um homem e uma mulher) que pontuaram as principais diferenças entre eles com intuito de ser referência para uma escolha mais assertiva. Além disso, a participação dos coordenadores sinalizou o apoio institucional tanto a realização da oficina quanto a presença feminina nos cursos. Posteriormente, o projeto Gurias na Computação foi apresentado e o vídeo "Elas nas exatas"1 foi exibido para ilustrar a importância da participação feminina.

Na etapa Computação, os conceitos de Computação e algoritmos foram definidos utilizando linguagem simples, mostramos exemplos de problemas próximos à realidade das meninas que podem ser resolvidos com a Computação, e mulheres protagonistas na área foram apresentadas: Ada Lovelace, Hedy Lamarr, Steve Shirley e Camila Achutti. A escolha de Camila Achutti, brasileira e contemporânea, teve como propósito facilitar a identificação das estudantes. Adicionalmente, as protagonistas foram relacionadas ao mundo dos quadrinhos, conforme ilustrado na Figura 1.

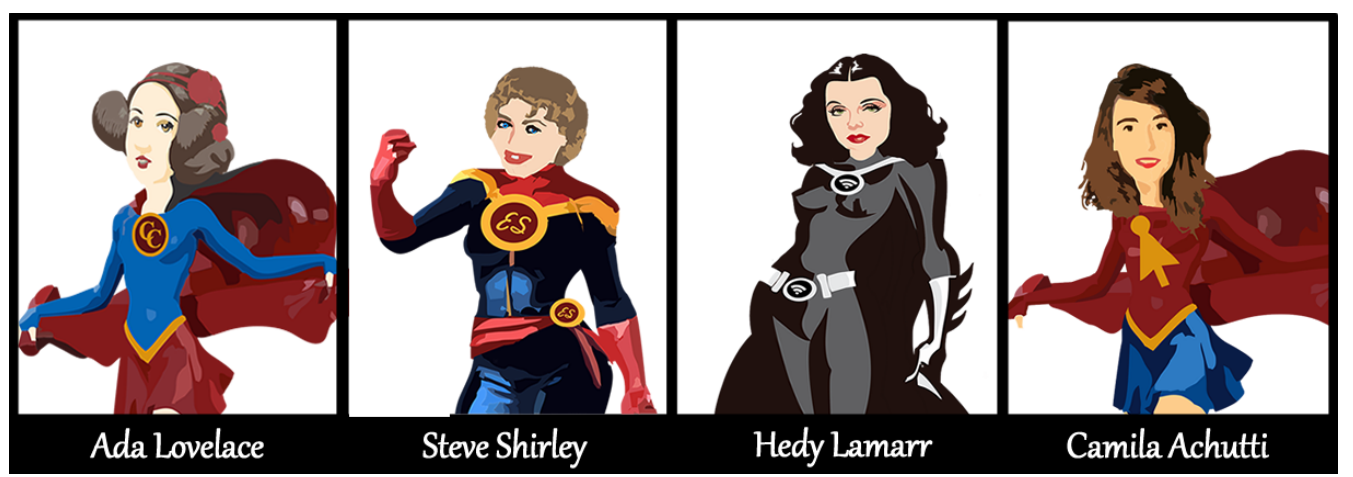

Figura 1. llustração das protagonistas

$\mathrm{Na}$ etapa Experimentação, o objetivo foi promover o contato inicial entre as estudantes e o mundo da Computação e seus algoritmos. Esta etapa foi iniciada na sala tradicional utilizando a Computação desplugada. Para essa atividade, a lição 1 do curso $\mathrm{D}$ da plataforma code. org $^{2}$ foi escolhida e traduzida. Essa lição consiste em pintar casas de uma grade 4x4 seguindo instruções de deslocamento e pintura. Nessa atividade, as estudantes foram divididas em grupos. No primeiro momento, cada grupo pintou as grades em branco seguindo os passos dos algoritmos fornecidos. A solução passo-a-passo desses algoritmos foi exibida utilizando animação. No segundo momento. foi fornecido grades já pintadas e solicitado que cada grupo escrevesse algoritmos capazes de gerá-las, além de verificar o correto funcionamento através da execução em grades em branco.

\footnotetext{
${ }^{1}$ https://www youtube.com/watch?v=N1 zKswyQId8

${ }^{2}$ https://curriculum.code.org/csf-18/coursed/1/
} 
Continuando a etapa Experimentação, um dos laboratórios de informática da Universidade foi utilizado para que cada estudante desenvolve-se a programação com blocos. Essa atividade inicio no estágio 1 do jogo 3 da plataforma code.org ${ }^{3}$. À medida que as participantes foram avançando os estágios, elas puderam praticar outros jogos com maior nível de dificuldade. Essa atividade foi realizada individualmente para que cada estudante a desenvolvesse em seu ritmo.

Na etapa Encerramento, foi aplicado um questionário de avaliação e exibido o vídeo final ${ }^{4}$, visando a mostrar que as estudantes podem aprofundar seus conhecimentos em Computação através de materiais disponibilizados gratuitamente na Internet.

Em relação à divulgação, oito escolas públicas do município de Alegrete foram visitadas pelas graduandas da equipe executora. Panfletos contendo o link para o formulário de inscrição foram distribuídos, assim como foi utilizado um formulário de inscrição físico durante a visita. Na inscrição, foram solicitados nome, idade, escola, série e uma forma de contato (e-mail e/ou telefone). O contato foi usado para enviar lembretes sobre a realização da oficina. A ordem de inscrição foi escolhida para selecionar as estudantes.

\section{Resultados}

A oficina realizada no dia 28 de novembro de 2018 recebeu 57 inscrições. Entretanto, apenas 12 meninas compareceram. Destas, 7 haviam se inscrito através do formulário online (53,85\% de comparecimento) e 5 através do formulário físico (11,36\% de comparecimento), indicando que muitas se inscreveram durante a divulgação por impulso. $\mathrm{Na}$ análise dos motivos para a baixa adesão, dois fatores colaboraram: $(i)$ data de realização muito próxima ao fim do ano letivo e (ii) a ausência do envolvimento de profissionais da escola na divulgação e execução da oficina.

As participantes da oficina possuíam idades entre 14 e 18 anos e eram originárias de 5 escolas, sendo $66,7 \%$ matriculadas no $1^{\circ}$ ano, $8,3 \%$ no $2^{\circ}$ ano e $25 \%$ no $3^{\circ}$ ano. Ao responderem o questionário de avaliação, todas indicaram terem gostado da oficina e que a Computação é uma área tanto para homens quanto para mulheres. Ao serem questionadas se já haviam visitado a Universidade, 66,7\% responderam que sim e 33,3\% responderam que não. Quando perguntadas se fariam um curso de graduação na área da Computação, $41,7 \%$ responderam que sim e 58,3\% responderam talvez. Dentre as percepções redigidas no espaço para elogios, críticas e sugestões destacam-se: "Eu gostei muito, porque é uma grande oportunidade de saber mais dos cursos de nossa cidade", "Achei a oficina muito interessante porque mostra que a mulher pode fazer o que ela quiser!", e "Achei interessante a possibilidade de poder conhecer o curso, com isso pude então formar um conceito mais elaborado sobre o mesmo, fazendo assim com que minha decisão em um futuro não tão distante seja feita de forma mais eficiente".

\section{Considerações Finais}

A oficina proporcionou às estudantes do Ensino Médio um momento de aprendizado e iniciação à Computação com o apoio de docente e graduandas da área. Adicionalmente, permitiu que a problemática da representatividade feminina fosse discutida. A equipe

\footnotetext{
${ }^{3}$ https://studio.code.org/s/course2/stage/3/puzzle/1

${ }^{4}$ http: //institutomarcoandreotti.org.br/codewars.php
} 
executora, ao apresentar a Computação com um espaço possível de atuação profissional, percebeu-se contribuindo para a transformação da sociedade e se fortaleceu como grupo.

A realização dessa oficina e de inúmeras ações em todo o Brasil ainda não modificaram a realidade atual: temos um número baixo de meninas ingressando e concluindo os cursos de Computação. No entanto, estamos fazendo um trabalho necessário e esperamos que em um futuro breve mais mulheres percebam o poder transformador da Computação.

Todo o material produzido para a oficina possui licença Creative Commons $(\mathrm{CC}$ BY-NC-SA 4.0) e pode ser acessado em http: / / bit. ly / oficinaGurias. Como trabalho futuro, destaca-se o aprimoramento do questionário de avaliação, além do estabelecimento de parcerias com profissionais da Educação Básica para que mais meninas sejam atingidas.

\section{Referências}

Ferrão, I., Mello, A., and Melo, A. (2017). Gurias na computação: fortalecendo e incentivando a participação feminina no ensino superior. In $11^{\circ}$ Women in Information Technology (WIT 2017), volume 11. SBC.

Moura, A., Tavares, T., Mattos, G., and Moreira, J. (2018). Incentivando alunas do ensino médio a ingressarem em carreiras de ciência e tecnologia na paraíba. In $12^{\circ}$ Women in Information Technology (WIT 2018), volume 12. SBC.

Neto, P. and Casagranda, M. (2017). Relatos de experiências da participação de mato grosso no technovation challenge 2017. In $11^{\circ}$ Women in Information Technology (WIT 2017), volume 11. SBC.

Ridel, D., Tridico, S., Branco, L., Maldonado, J., and Branco, K. (2018). Technovation hackday @icmc-usp um instrumento de difusão e articulação de meninas na computação. In $12^{\circ}$ Women in Information Technology (WIT 2018), volume 12. SBC.

Salgado, L., Cappelli, C., and Avelino, M. (2017). Oficina de re(design) da interação do whatsapp para alunas da rede municipal de petrópolis. In $11^{\circ}$ Women in Information Technology (WIT 2017), volume 11. SBC.

Santos, C., Rodrigues, D., Ferreira, G., and Silveira, M. (2017a). Explorando o pensamento computacional para despertar novos talentos: Relato de uma experiência. In $11^{\circ}$ Women in Information Technology (WIT 2017), volume 11. SBC.

Santos, J., Ferreira, A., Oliveira, A., Santos, D., and Matos, E. (2017b). Meninas digitais - regional bahia: os primeiros bits. In $11^{\circ}$ Women in Information Technology (WIT 2017), volume 11. SBC.

SBC (2017). Educação superior em computação estatísticas 2017. http : / / www . sbc . org.br/documentos-da-sbc/category/133-estatisticas. Acessado: 20-03-2019.

Silva, T. and Silva, G. (2018). Programando para inclusão - experiências e lições aprendidas. In $12^{\circ}$ Women in Information Technology (WIT 2018), volume 12. SBC.

Soares, C., Leite, L., Araujo, A., and Holanda, M. (2018). Mulheres de ferro: Relato de prática utilizando arduíno com alunas do ensino médio em uma escola pública. In $12^{\circ}$ Women in Information Technology (WIT 2018), volume 12. SBC. 